Córima, Revista de Investigación en Gestión Cultural

ISSN electrónico: 2448-7694

Universidad de Guadalajara

Sistema de Universidad Virtual

México

corima@udgvirtual.udg.mx

Año 3, número 5, julio-diciembre 2018

\title{
Paces imperfectas para el perdón y la reconciliación en Colombia
}

\author{
Diana Carolina Calle Valencia ${ }^{1}$ \\ Mario Hernán López Becerra \\ Universidad de Caldas, Colombia
}

DOI: $10.32870 /$ cor.a3n5.7202

[Recibido: 28/04/2018; aceptado para su publicación: 19/06/2018]

\section{Resumen}

Este artículo es parte de una investigación realizada en Colombia sobre la construcción de la paz imperfecta en el marco de los conflictos generados por acciones de secuestro en dos regiones del país. La investigación se basó en el estudio de tres casos de pérdida de la libertad y se desarrolló bajo un enfoque metodológico cualitativo y epistemológico fenomenológico; la principal conclusión de esta pesquisa fue la posibilidad de construir acciones de paz, aun en la adversidad. El punto de partida son los apartados teóricos y conclusivos de la investigación y contiene un conjunto de reflexiones alrededor de tres ejes centrales: en primer lugar, se exponen algunos antecedentes y alcances de los acuerdos

\footnotetext{
${ }^{1}$ Correo electrónico: carolinacallevalencia@gmail.com
}

CÓMO CITAR ESTE ARTÍCULO:

Calle Valencia, D., López Becerra, M. (2018). Paces imperfectas para el perdón y la reconciliación en Colombia. Córima, Revista de Investigación en Gestión Cultural, 3(5). doi: $10.32870 /$ cor.a3n5.7202 
firmados entre el gobierno colombiano y las guerrillas de las FARC, así como un panorama rápido de los diálogos en curso entre el gobierno y la guerrilla del ELN. En segundo lugar, el artículo presenta una consideración teórica y conceptual sobre los conflictos y las paces desde la perspectiva de la paz imperfecta; por último, indaga acerca del papel que cumplen las regulaciones y transformaciones pacíficas en la construcción del perdón y la reconciliación, como condiciones para la construcción de paces estables y duraderas.

\section{Palabras clave}

Conflictos, paz imperfecta, perdón, reconciliación, procesos de paz, cultura.

\section{Introducción}

En la actualidad colombiana, la posibilidad de lograr la paz política entre el Estado y la insurgencia armada se ha revelado como una oportunidad para superar más de cinco décadas de confrontación bélica. La disputa violenta por el poder ha arrojado cerca de ocho millones de víctimas, la cual involucra a múltiples actores y además ha evolucionado en función de los intereses de las élites nacionales y de los conflictos en los territorios. En términos de la taxonomía diseñada por el sociólogo y matemático noruego Johan Galtung (2003), se afirma que la sociedad colombiana ha vivido violencias directas, estructurales y simbólicas, y se han creado distintas formas de representación tanto para la guerra como para la paz.

Existen múltiples hipótesis en relación con los orígenes y causas de los conflictos sociales, además de la dinámica del conflicto armado; gran parte de ellas coinciden en señalar dos factores determinantes: la disputa por la tenencia de la tierra y la incapacidad del estado neoliberal para agenciar una sociedad más justa e igualitaria. Entre los señalamientos recurrentes a las responsabilidades que atañen al Estado y a las élites nacionales y regionales, se suele plantear la incapacidad para crear una nueva realidad política que permita transformar las condiciones impuestas por la vieja democracia hereditaria (Pécaut, 2001). En su fase más reciente, el conflicto de armas está asociado a los intereses que desataron las economías ilegales y las disputas por el poder social, económico y político en los territorios.

Este artículo presenta un contexto introductorio acerca de la confrontación armada, sus actores e impactos humanitarios; fija la mirada en algunos contenidos y despliegues de los acuerdos entre el gobierno nacional y un sector de las insurgencias que han logrado una salida política, el centro de la reflexión se encamina a reconocer el potencial para el perdón y la reconciliación que ofrece el 
enfoque de la paz imperfecta, entendida como capacidades humanas y sociales creadoras, originadas en medio de conflictos y violencias (Muñoz, 2004).

En los últimos años las formas de representación de la paz en Colombia han estado ligadas a la interpretación que realizan los distintos sectores sociales acerca de los alcances de los acuerdos logrados entre una parte de la insurgencia armada y el gobierno nacional. De acuerdo con Anrup (2011), Colombia se encuentra, en la actualidad, en una situación de apariencia paradójica, del mismo modo que con los acuerdos recientes se configuran distintas formas de representación de la paz, con las cuales se detonan otros conflictos sociales, culturales y políticos, también los imaginarios colectivos han estado fuertemente orientados a la superación de las violencias. En consecuencia, la búsqueda de la paz es, al mismo tiempo, un dispositivo de unión y división social, cultural y política.

De acuerdo con Muñoz (2004), en Colombia se ha creado un imaginario que vincula de forma indeleble la paz con la finalización de la guerra sin considerar que, pensada en sentido polisémico, la paz es también una realidad humana y social en la cual se comprometen múltiples formas de interacción social y cultural, necesarias para avanzar en el proceso de reconciliación.

\section{Metodología}

La tesis de partida de esta investigación (de la cual se deriva este artículo de reflexión), plantea la necesidad de realizar estudios sobre la construcción de la paz desde la fenomenología. En ella se advierte que los seres humanos comprenden el mundo y sus fenómenos en la medida de sus experiencias y relaciones con los otros (Schutz, 2003). Por lo anterior, la intencionalidad epistemológica de la investigación fue comprender desde la fenomenología cómo se entienden los conflictos y la construcción de la paz imperfecta desde las experiencias, a partir de la aceptación de la existencia de semejantes que integran el mundo.

En términos generales, la investigación se centró en el conflicto colombiano, cuyos actores se localizan en las guerrillas de las Fuerzas Armadas Revolucionarias (FARC) y el Ejército de liberación Nacional (ELN), quienes han hecho uso de distintos métodos violentos como los secuestros, las extorsiones y los desplazamientos. La unidad de trabajo fueron tres casos de estudio mediante los cuales fue posible examinar si estos conflictos violentos pueden ser transformados positivamente para generar procesos de construcción de paz imperfecta que desemboquen en acciones de perdón y reconciliación. 
En los estudios acerca de la paz imperfecta, realizados por Francisco Muñoz, Vicent Martínez y Sonia París, entre otros investigadores, plantean un giro epistemológico a partir de la fenomenología de la intersubjetividad. En este contexto el centro de la indagación son las construcciones pacíficas que crean los sujetos s sus capacidades para la regulación de los conflictos y la superación de las violencias.

\section{Paces imperfectas para el perdón y la reconciliación en Colombia}

\section{Acuerdos y desacuerdos en la búsqueda de paz social y política}

Los últimos años han sido decisivos para construir un presente y futuro distintos para los colombianos; gran parte de la agenda desplegada en los debates públicos y en las movilizaciones sociales ha estado centrada en temas relacionados con los alcances e implicaciones de los procesos de diálogo entre las guerrillas y el gobierno, así como en los contenidos finales de los acuerdos de paz. Para comprender los desafíos que deben ser sorteados para avanzar hacia la reconciliación y el perdón, se describen algunos de los momentos, conflictos y procesos que han rodeado los diálogos y acuerdos para la terminación del conflicto armado en Colombia.

El 28 de agosto de 2012 se abrieron las mesas de diálogos entre representantes del gobierno y de la guerrilla de las FARC. Después de casi seis años se lograron acuerdos sobre seis temas centrales: políticas de desarrollo agrario, participación política, fin del conflicto, solución al problema de las drogas ilícitas, acuerdos sobre las víctimas del conflicto, y se definieron mecanismos de implementación, verificación y refrendación de los acuerdos.

En términos generales, los alcances y contenidos de los seis temas acordados pueden ser valorados tanto en términos de paz negativa (terminar la guerra y avanzar en la erradicación de la violencia directa), como en la construcción de paz positiva para la superación de las desigualdades. A juicio de Vicent Fisas (2017), el acuerdo de paz "abre un inmenso espacio para desarrollar la democracia, mejorar las condiciones de vida del campesinado, atajar el problema del narcotráfico y avanzar en la reducción de las desigualdades" (p. 13).

En los diálogos de La Habana de 2015 se concretó un acuerdo sobre los alcances y dispositivos de la justicia transicional entre el gobierno y las FARC; se estableció la firma del documento definitivo para el 23 de marzo de 2016. En materia de justicia transicional, el acuerdo parcial planteó la creación de una jurisdicción especial para la paz cuyo propósito es conocer la verdad de los hechos, 
transformar el estado de impunidad generalizada en el país, contribuir a la reparación de las víctimas y juzgar e imponer sanciones a los responsables de delitos de lesa humanidad, cometidos durante la confrontación armada.

El 24 de junio de 2016 las FARC y el gobierno nacional firmaron el texto definitivo que contiene un conjunto de acciones para detener la violencia directa asociada al conflicto armado (paz negativa), lo cual incluye el cese al fuego y de hostilidades bilaterales y definitivas, así como la dejación de las armas. En el mismo acuerdo se definieron las zonas de ubicación de las tropas guerrilleras para la verificación del cese bilateral de los ataques; también se diseñó el cronograma de la dejación de armas y las garantías de seguridad para los excombatientes.

En este mismo año, el jefe de Estado planteó la necesidad de convocar a los colombianos para que se manifestaran de acuerdo con lo pactado entre los representantes del gobierno nacional y los negociadores de las FARC, se advirtió con insistencia que el mecanismo democrático de participación ciudadana sería un plebiscito, mediante el cual se apoyaría o rechazaría la decisión del ejecutivo en relación con la firma de los acuerdos de paz. El plebiscito fue convocado en el marco del artículo 7 de la Ley 134 de 1994; por lo cual, el 2 de octubre de 2016 los ciudadanos fueron a las urnas con el propósito de respaldar o no los contenidos del acuerdo final.

La Registraduría Civil de la Nación (2016) indicó que 34899945 personas estaban habilitadas para votar, pero solo 13066047 se acercaron a las urnas (el $37.43 \%$ del potencial sufragante); se reportó un alto registro de abstención electoral en comparación con las últimas dos décadas. Pese a los pronósticos, casi siempre favorables al acuerdo y a los cálculos anticipados por parte de los analistas políticos, más del $50 \%$ de los ciudadanos que participaron en el plebiscito votaron por el no. Los análisis de los resultados por parte de los especialistas dieron cuenta de las implicaciones institucionales de la decisión ciudadana, del enorme obstáculo generado para la implementación de los acuerdos y del asombro internacional provocado por la decisión de los ciudadanos colombianos (Semana, 2016)

Sin ser una cifra muy superior a los sufragantes del sí, 6431376 de personas votaron para evitar la puesta en marcha del acuerdo. Más allá de las expectativas del gobierno por lograr una refrendación ciudadana que legitimara el conjunto de propuestas para la paz, el plebiscito se constituyó como un factor que ha obstaculizado la reconciliación de los colombianos, más que un proceso de creaciones y movilizaciones colectivas a favor de la reconciliación, el plebiscito fue un pulso entre dos sectores políticos (De Roux, 2018). 
Los opositores criticaron no haberse sentido plenamente satisfechos con los contenidos pactados, especialmente en temas relacionados con los alcances de la justicia para los guerrilleros, la financiación del partido político de las FARC, la creación de nuevas curules en el Congreso de la República y la eventual entrega del país a las guerrillas; desde esa óptica, se consideraba que el acuerdo también atentaba contra la propiedad privada y la dignidad de las fuerzas militares (Acevedo Carmona, 2016).

Ante los resultados adversos del plebiscito, el gobierno buscó sortear el conflicto político con la creación de mesas de diálogo con la oposición para ajustar los contenidos del texto; en el mes de noviembre se propuso un nuevo contenido que incluyó propuestas de los sectores que se opusieron al documento inicial y que buscaba incorporar gran parte de las exigencias de los detractores para ser de nuevo discutidas en la mesa de negociación. Superado a medias el impase, en el mes de diciembre de 2016 la Corte Constitucional aprobó un procedimiento especial para el trámite legislativo conocido como fast track, un mecanismo que permitía generar una vía rápida en el Congreso para tramitar las leyes y realizar las reformas necesarias para implementar el nuevo acuerdo político para la terminación del conflicto y la construcción de una paz estable y duradera.

En 2017 se realizó la fase final del acuerdo en materia de desmovilización; el 30 de enero del mismo año los guerrilleros se dirigieron hacia las 26 zonas veredales pactadas con el gobierno para dejar las armas y empezar su tránsito hacia la vida civil. Al mismo tiempo que se producía la desmovilización, la esperanza de la paz política se fue transformando en nuevas formas de conflicto político y crispación social. En suma, los diálogos y la firma del Acuerdo final fueron un proceso conflictivo que evidenció distintas muestras simbólicas de la paz entre los colombianos.

En la creación de las nuevas representaciones de la paz jugó un papel determinante el despliegue eficaz de estrategias comunicacionales por sectores políticos interesados en lograr la justicia penal para reparar los daños de las víctimas. Más adelante estas tensiones se convertirían en enormes dificultades para el perdón y la reconciliación como bases para la transición hacia una sociedad más pacífica.

Como parte de las acciones para terminar el conflicto, el gobierno nacional y las FARC se comprometieron a "contribuir al surgimiento de una nueva cultura que proscriba la utilización de las armas en el ejercicio de la política" (Acuerdo final, 2017, pp. 103- 104). En este marco, los exguerrilleros conformaron el partido político Fuerza Alternativa Revolucionaria del Común (FARC). La transición de las 
guerrillas hacia la democracia formal ha sido un proceso que deja aprendizajes y enseñanzas que permiten continuar en el propósito de reducir cada vez más las violencias directas, estructurales y simbólicas, al tiempo que concita reflexiones sobre las procedimientos, contenidos y alcances de los futuros diálogos y acuerdos eventuales con otros sectores de la insurgencia armada.

El segundo proceso de paz que se lleva a cabo actualmente involucra a la guerrilla del Ejército de Liberación Nacional (ELN) y al gobierno nacional. El ELN, en su origen, involucró universitarios y sacerdotes católicos que optaron por la lucha armada como vía para transformar las condiciones de injusticia y explotación imperantes (Hernández, 2004).

El origen de esta guerrilla se ubica a mediados de los años sesenta como parte del influjo que tuvo la revolución cubana sobre los procesos de emancipación social en América Latina. Su reivindicación política inicial se enfocó en la transformación de las condiciones de explotación, en la superación de la exclusión social, económica y política y en combatir la distribución desigual de la tierra; sus acciones más publicitadas se relacionan con la voladura de oleoductos como forma radical de denuncia ante las políticas imperantes en la explotación petrolera.

En los años sesenta, el ELN empezó a exigir millonarias sumas de dinero por la libertad de líderes políticos, ganaderos, ejecutivos de multinacionales, hombres de familia de tradición en la región, y diplomáticos (Medina, 2010). Según estadísticas del Centro Nacional de Memoria Histórica (2013) "del año 1970 a 2010, se presentaron 39058 casos de personas secuestradas, de las cuales el 25\% son atribuidos al ELN" (p. 12). Después de intentos infructuosos de diálogos del ELN por parte de gobiernos anteriores, la Oficina del Alto Comisionado para la Paz informó que a partir del 8 de febrero de 2017 se instalaría en Quito (Ecuador) la mesa de diálogo entre el gobierno nacional, bajo la presidencia de Juan Manuel Santos, y el Ejército de Liberación Nacional, se buscó alcanzar un acuerdo definitivo para una paz política completa.

Según la Oficina del Alto Comisionado para la Paz (OACP), el 6 de junio de 2017 las delegaciones del gobierno y del ELN, en el segundo ciclo de conversaciones, acordaron constituir un equipo conjunto de pedagogía y comunicación para la paz con el objetivo principal de promover la construcción de culturas de paz a partir de la generación de confianza y credibilidad, como parte del aprendizaje que dejaron los acuerdos con las FARC.

En septiembre de 2017 se acordó desarrollar un cese al fuego bilateral y temporal para reducir la intensidad del conflicto armado y mejorar la situación humanitaria de la población en los territorios afectados por la confrontación armada. 
El cese al fuego se llevó a cabo desde el 1 de octubre de 2017 al 9 de enero de 2018; no solo se evitó el uso de armas de fuego sino de cualquier tipo de hostilidades. Además, la guerrilla se comprometió a suspender cualquier secuestro contra ciudadanos nacionales o extranjeros, a suspender todo atentado contra la infraestructura del país, incluidos los oleoductos que han sido objetivos primordiales en sus ataques y los cuales han dejado consecuencias ambientales negativas por los miles de barriles de petróleo derramados sobre aguas y tierras, lo que impactó la flora, la fauna y el acceso al agua de las poblaciones afectadas (López \& Calle, 2017).

En los acuerdos iniciales, los insurgentes también se comprometieron a frenar los reclutamientos de menores y de abstenerse a instalar artefactos antipersonales que pusieran en peligro la vida de la población civil. Por su parte, el gobierno se comprometió a fortalecer el sistema de alertas tempranas para la protección a los líderes sociales y adelantar programas de carácter humanitario en las cárceles para los militantes del ELN, lo cual mejoraría sus condiciones de vida (OACP).

Durante los días del cese al fuego, tanto el ELN como el gobierno se acusaron mutuamente de incumplimientos, lo cual terminó en el asesinato del gobernador indígena Aulio Isarama Forastero por parte de esta guerrilla, quienes posteriormente pidieron perdón a la comunidad. No obstante, hay que aclarar que en el tiempo de tregua no se reportaron enfrentamientos entre militares y guerrilleros, una situación inédita en cinco décadas de confrontación armada. Unos meses después de finalizado el cese al fuego (12 de marzo de 2018) se anunció una nueva posibilidad de apertura a los diálogos con este grupo y representantes del gobierno nacional.

Tanto los acuerdos logrados con las FARC, como los avances conocidos públicamente en las mesas de negociaciones con el ELN, han generado expectativas positivas en un sector de la sociedad colombiana que se ha movilizado a favor de las salidas negociadas al conflicto armado; al mismo tiempo, ambos procesos han generado descontento en un sector sociopolítico que cuestiona las condiciones propuestas en la justicia transicional $y$, en su lugar, reclama un mayor castigo para los victimarios.

En síntesis, la firma del acuerdo final para la terminación del conflicto y la construcción de una paz estable y duradera abrió caminos para nuevos diálogos con sectores insurgentes y arrojó mejores metodologías para diseñar procesos de transición con participación directa de las víctimas; también dejó importantes aprendizajes de los errores cometidos en el proceso de refrendación y facilitó el diseño de mecanismos más expeditos para evitar impunidades y violaciones en lo 
acordado por ambas partes. Para el sacerdote Francisco de Roux (2018), más allá de los diálogos y acuerdos, la reconciliación entre los colombianos constituye el mayor desafío en la conquista de la paz.

\section{Lo que se puede aprender acerca de los conflictos y las paces}

Los conflictos suelen ser definidos de manera convencional como sinónimos de guerras y violencias, como anuncios de destrozo y muerte, como expresiones del daño que los seres humanos se infringen entre sí. La palabra conflicto, según la Real Academia Española de la Lengua, tiene origen en la palabra latina conflictus, que significa combate, lucha o pelea, quizá por este tipo de definiciones la acepción más convencional se enfoca en las actuaciones agresivas, provocadoras, ofensivas, violentas, de contradicción, de oposición, de diferencia y de competencia.

En el giro epistemológico propuesto en el marco de la investigación de y para la paz (Martínez, 2005), se considera que los conflictos no son sinónimos de actuación violenta; desde esta perspectiva la violencia es un tipo de regulación en el cual una de las partes se impone sobre la otra. Por tanto, los conflictos también pueden ser regulados, gestionados y transformados a partir de medios pacíficos, lo que da paso a múltiples experiencias de paz, aun en medio de violencias. Los conflictos pueden ser presentados como problemas, diferencias, obstáculos, tensiones 0 intereses contrapuestos que emergen tanto en las relaciones intersubjetivas como en las formas de organización, interacción, representación y movilización social.

La regulación pacífica de los conflictos implica que los seres humanos podemos interactuar y responder a los intereses contrapuestos con una amplia gama de alternativas.

La regulación supone que el conflicto no termina con su actuación pero que las partes reconocen en qué situación se encuentran, cuáles son las causas, y deciden hacer algunos cambios, especialmente en normas de conducta, actitudes y estructuras, que ayudan a establecer una nueva situación lo menos violenta posible (Muñoz, 2004, p. 177).

Los conflictos, como antesala de una experiencia de paz, pueden clasificarse a partir de cómo son regulados, gestionados o transformados. Sonia Paris Albert (2009), filósofa e investigadora en estudios para la paz, explica: "los conflictos no son positivos ni negativos en sí mismos, sino que su carácter depende de los medios usados para su regulación" (p. 13). 
El conflicto que ha sido regulado de manera negativa (violento) es aquel que se proyecta de forma individualista y egoísta, cuyo propósito es satisfacer el interés de una de las partes implicadas; esto genera nuevos conflictos y violencias escaladas, cuyas acciones y efectos serán destructivos o discriminatorios. Examinados desde otra óptica, los conflictos que han sido regulados de manera pacífica acompañan gran parte de la historia de los seres humanos en cuanto han posibilitado tramitar las diferencias en sus vidas sin apelar a las violencias; de modo que la cultura de paz supone construir hábitos, tradiciones, saberes y estilos de vida basados en la gestión, la regulación y la transformación positiva de la conflictividad.

Los conflictos adquieren una dimensión positiva (pacífica), cuando en las relaciones entre los seres humanos, siempre en tensión, se privilegian las formas de interacción basadas en el diálogo, en la socialización e interpretación conjunta de los factores que generan los conflictos, al tiempo que se opta por formas de regulación no violenta.

Como conclusión integradora de los temas expuestos hasta ahora, la mayoría de la sociedad colombiana considera que la firma de los acuerdos es un paso necesario hacia la construcción de paces políticas y sociales; no obstante, para alcanzar una paz estable y duradera no resultan suficientes la dejación de las armas y las acciones en materia de paz negativa; la paz, como lo señala Galtung (2003), está asociada a la justicia y al bienestar, al tiempo que es necesario construir otros repertorios culturales necesarios para la búsqueda del perdón y la reconciliación.

\section{Caminos posibles para el perdón y la reconciliación}

La creación de culturas de paz es una tarea compleja; se trata de un reto aún más exigente en escenarios de violencias multidimensionales. Es compleja en sentido filosófico e intrincada en términos políticos por la multiplicidad de actores y situaciones, así como por los distintos intereses en juego.

Desde una perspectiva convencional, la paz se presenta como la luz al final del túnel en el camino de los conflictos y las violencias; también se idealiza como solución definitiva en el entramado de experiencias conflictivas que tenemos los seres humanos en el transcurso de la vida. De manera convencional, es asociada a la solución total después de los conflictos. La noción utópica de la paz como ausencia de conflictos y violencias, es interpelada por otras perspectivas epistemológicas que invitan a pensarla en un campo de estudio que tiene como punto de partida a la paz por la paz. 
Algunos investigadores como Martínez (2005), proponen un giro epistemológico apoyado en la fenomenología de la intersubjetividad, en el cual la paz puede ser concebida con una mirada distinta desde el pensamiento, el sentimiento, la comprensión y la interpretación, lo que rompe la línea en la que se investiga desde lo que no es, es decir desde las violencias. El giro epistemológico no se enfoca en la ausencia o eliminación de los conflictos, en su lugar da paso a una comprensión de las capacidades y competencias empáticas inherentes de los seres humanos para proponer regulaciones $y$ transformaciones positivas de las contradicciones.

En este giro epistemológico las relaciones son intersubjetivas; el mundo está configurado por la posibilidad de comprender a los otros en sus acciones, experiencias, actitudes, aptitudes, imperfecciones e intereses; lo cual desemboca en la conformación de un sujeto de comprensión y un sujeto que comprende. Las paces (en un sentido polisémico y diverso) son mucho más que el silencio de las armas, del mismo modo que son imperfectas porque conviven con los conflictos y las violencias.

Como se planteó en el contexto inicial, la historia de Colombia ha estado caracterizada por una dinámica de conflictos y violencias entrecruzadas, lo que indica - como en el caso de los debates recientes acerca de los procesos de paz- la presencia de emociones fuertemente inscritas en las conflictividades recientes: se trata de fuerzas poderosas, detonantes de respuestas subjetivas y colectivas como el rencor, la venganza, la exclusión, la victimización y la incomprensión, entre muchas otras; lo que obstaculiza el avance hacia vivencias profundas en la construcción de paces. La violencia consume y horada, la paz restaura y aproxima.

En su libro Filosofía de los conflictos (2009), Sonia París señala que el empleo de medios pacíficos da lugar a una visión positiva del conflicto al permitir transformar las tensiones y generar nuevos objetivos que favorecerán la continuidad de las relaciones en el presente y el futuro. Este planteamiento contribuye a esclarecer las rutas para trabajar en el perdón y la reconciliación como paso hacia nuevas y otras experiencias de paces. Perdonar es un proceso personal, interior e interpersonal de resignificación de sentimientos y dolores que han sido causados por distintos eventos; quien perdona toma el camino del sobreviviente.

El perdón, en primera instancia, debe suponer que el ofensor reconoce su culpabilidad, lo cual anuncia un perdón propio; en segunda instancia, quien es ofendido manifiesta su capacidad libre de desencadenarse del dolor causado, lo que le permite alejarse del deseo de infligir daño al otro. El perdón no puede ser producto de la fuerza, es una decisión libre entre el ofendido y el ofensor para 
reestablecer las relaciones interpersonales quebrantadas y supone una profunda bondad, generosidad y expresión de amor de quien lo otorga.

El rencor, el despecho, el deseo de venganza o el odio, puede entorpecer y romper cualquier intento de reencauzar una relación. Los deseos destructivos asociados a estos sentimientos impiden que las partes se centren en la defensa de sus intereses y, más bien, intenten conseguir el máximo perjuicio y mal para el adversario. Esos núcleos emocionales, además impiden la comunicación eficaz y fluida entre las partes. (Muñoz, 2004, p. 209).

Diseñar y operar métodos de regulación pacífica en diferentes conflictos implica buscar la restauración interpersonal de las relaciones a fin de prevenir futuros conflictos negativos, de allí la importancia de construir paces a partir del perdón, esto no indica fragilidad emocional o flaqueza de carácter. En palabras de Sandrine Lefranc (2005), el perdón no es sinónimo de olvido, es instante y acontecimiento: "Para perdonar es preciso recordar; el olvido es transcurso del tiempo (intervalo), desgaste del recuerdo, el perdón es instante, acontecimiento: es hacer, accionar y no reaccionar. Entre el instante y el intervalo se juega la libertad del hombre, su libre culpabilidad" (pp. 174-175).

Perdonar transforma los sentimientos generados y guardados en la memoria sensible, es allí donde se pueden crear espacios de contacto entre las partes en conflicto (víctimas y victimarios, ofensores y ofendidos); la memoria necesita ser sanada. En espacios de conflicto, el recuerdo genera la necesidad de su existencia para cerrar las puertas del odio.

Pensada en clave de paz imperfecta, la construcción de memoria colectiva en conflictos violentos exacerbados como los que ha vivido Colombia, se debe orientar al esclarecimiento de la verdad acerca de los hechos victimizantes, al conocimiento de los hechos verdaderos y a las causas de sus experiencias dolorosas, pero también al recuerdo de los procesos y construcciones de paz, a las realizaciones colectivas que permiten ampliar la memoria con los logros compartidos en el pasado.

La memoria colectiva o histórica es producto de un proceso colectivo, de la creación de un lenguaje y significación común a los miembros de una sociedad de forma tal que, cuando vuelvan al pasado, lo hagan de forma combinada, dotándose a sí mismos de un sentido compartido de ciertos eventos que, poco a poco, se van constituyendo como parte fundamental de su identidad. Uno de los elementos que, quizá, han contribuido a la indiferencia con respecto al conflicto armado interno colombiano, hace referencia a la falta de memoria, y de memoria histórica (Aguirre J, 2015). 
En el libro Manual de paz y conflictos (2004), Francisco Muñoz sostiene que la paz es un signo de bienestar, felicidad y armonía que nos une a los demás; a su juicio, la paz actúa como vacuna que previene el egoísmo, el individualismo y el desprecio hacia los otros. De manera que la reconciliación supone optar por salidas no violentas a los conflictos colectivos, así como construir relaciones basadas en la comprensión, aceptación, respeto y reconocimiento de las imperfecciones inherentes a los seres humanos. Como estrategia para transformar la conflictividad, la reconciliación también implica resignificar los contenidos y las formas convencionales de justicia.

El castigo no es una manera sana de aplicar justicia sino un modo ciego de oficializar la cultura bárbara de la venganza. Es justo que quien cometa un delito pague una pena, pero el objetivo último de esa debería ser la recuperación del culpable y no como sucede con frecuencia, su ruina definitiva (Narváez \& Armato, 2016, p. 14).

\section{Conclusión}

En la investigación que sirve como punto partida para este artículo, se concluyó que los actos violentos como el secuestro, rompen la relación intersubjetiva que se propone desde la fenomenología, debido a que se anula el interés por la comprensión de la realidad de los otros, se pierde la noción del reconocimiento del valor intrínseco de las personas y por tanto no hay respeto a los derechos (la investigación examinó tres experiencias de secuestro por parte de guerrillas en dos regiones de Colombia).

En medio del drama humanitario también se producen otras realidades: la investigación identificó las capacidades desplegadas por las personas para empoderarse, lo que resignificó sus experiencias de dolor, con lo cual lograron poner en marcha estrategias para transformar las realidades violentas en realidades generativas.

El estudio de tres casos de personas en cautiverio, los relatos de los hechos y sus reflexiones posteriores sobre las acciones realizadas durante el cautiverio, así como el análisis de las actuaciones de los secuestradores y las movilizaciones y reacciones públicas, dio a conocer los repertorios y dispositivos empleados para transformar las condiciones de adversidad.

La paz imperfecta, como enfoque de investigación que invita a indagar en las capacidades creadoras en escenarios signados por conflictos y violencias, contribuyó 
a esclarecer las rutas para trabajar en el perdón y la reconciliación como paso hacia nuevas y otras experiencias de paces.

Los resultados de la investigación indican que una lección central del pacifismo consiste en reconocer que los actos no violentos empiezan a surgir en la medida en que hay reconocimiento del otro en la alteridad; el perdón es posible cuando en el espacio de encuentro de víctimas y victimarios existe la identificación mutua de seres humanos con sentimientos, dolencias, sueños $e$ intereses contrapuestos.

Ante el imperativo cultural de buscar la reconciliación en Colombia, se requiere crear y cultivar capacidades para reconocer y construir paces imperfectas; sin embargo, en procesos donde hay multiplicidad de intereses, opiniones, realidades, conflictos, posturas, ideologías, credos, políticas y muchas otras diferencias, no serán suficientes las negociaciones, acuerdos, arbitrajes o mediaciones si no se avanza colectivamente por el respeto a la vida y a los derechos humanos, lo cual implica desplegar una lucha colectiva por la justicia social.

Reconocer las capacidades creadoras en la adversidad y trabajar en la generación de paces imperfectas en todos los espacios de interacción social, abre paso a la construcción de nuevas realidades en las cuales se generan condiciones y dispositivos para el perdón, al tiempo que generan espacios colectivos de empoderamiento que son fundamentales para la tarea cultural de la reconciliación.

\section{Referencias}

Acevedo Carmona, D. (2016). Diez razones para votar No en el plebiscito. El tiempo. Recuperado de https://www.elespectador.com/opinion/opinion/diezrazones-para-votar-no-en-el-plebiscito-columna-651703

Acuerdo final. (2017). Acuerdo final para la terminación del conflicto y la construcción de una paz estable y duradera (2017). Bogotá, Colombia: Ediciones Desde Abajo.

Aguirre J, A. (2015). Por qué es importante la memoria histórica en Colombia. Revista Nova et Vetera.

Anrup, R. (2011). Antígona y Creonte: Rebeldía y Estado en Colombia. Bogotá: Crónica Ediciones B. 
Centro Nacional de Memoria Histórica. (2013). Una verdad secuestrada cuarenta años de estadísticas de secuestro. Bogotá: Imprenta Nacional. Obtenido de http://www.centrodememoriahistorica.gov.co/centro-

audiovisual/multimedias/una-verdad-secuestrada-cuarenta-anos-deestadisticas-de-secuestro-1970-2010

Civil, R. N. (2016). Registradura Nacional del Estado Civil. Obtenido de Registradura Nacional del Estado Civil: https://elecciones.registraduria.gov.co/pre_plebis_2016/99PL/DPLZZZZZZZZ ZZZZZZZZZ_L1.htm

Constitucional, C. (2017). Corte Constitucional. Obtenido de Corte Constitucional: http://www.corteconstitucional.gov.co/relatoria/2017/C-160-17.htm

De Roux, F. (2018). La audacia de la paz imperfecta. Ariel. Bogotá, Colombia. Bogotá, Colomba: Ariel.

Fisas, V. (2017). Negociar la Paz con las FARC. Una experiencia innovadora. Barcelona, España: Icaria.

Galeano Molano, M. E. (2004). Diseño de proyectos en la investigación cualitativa. Medellín: Universidad EAFIT.

Galtung, J. (2003). Paz por medios pacíficos. Paz y conflicto, desarrollo y civilización. Bilbao: Gernika Gogoratuz.

Hernández, M. (2004). Rojo Negro Aproximación a la Historia del ELN. Colombia: Dirección nacional ELN de Colombia.

Lefranc, S. (2005). Políticas del Perdón. España: Norma.

López, M. H., \& Calle, D. C. (Junio de 2017). Lo que falta para una paz política. Consideraciones sobre los diálogos con el ELN. Lumina Spargo.

Martínez, V. (2005). Podemos Hacer LAS PACES. Reflexiones éticas tras el II-S y el II-M . España: Desclée De Brouwer, S.A.

Medina, C. (2010). FARC-EP Y ELN Una historia política comparada (1958- 2006). . Tesis de doctorado. Bogotá: Universidad Nacional de Colombia.

Muñoz, F. (2004). Manual de paz y conflictos. España: Universidad de Granada. 
Narváez, L. \& Armato, A. (2016). La revolución del perdón. Manizales: Paulina.

OACP. (s.f.). Oficina del Alto Comisionado para la Paz. Obtenido de Oficina del Alto Comisionado para

la

Paz:

http://www.altocomisionadoparalapaz.gov.co/dialagos-

eln/Paginas/Comunicados-conjuntos/2017/Comunicado-Conjunto-3-

Acuerdos-en-ciclo-2.aspx

Paris, A. S. (2009). Filosofía de los conflictos- Una teoría para su transformación pacífica. Barcelona. Icaria Antrazyt Paz y Conflictos.

Pécaut, D. (2001). Guerra contra la sociedad. Colombia. Planeta.

Real Academia Española. (Octubre de 2014). Diccionario de la Lengua Española. Obtenido de Diccionario de la Lengua Española: http://dle.rae.es/?id=AGHyxGk

República, S. D. (s.f.). El senado de las causas sociales y la reconciliación. Obtenido de El senado de las causas sociales y la reconciliación: http://www.senado.gov.co

Schutz, A. (2003). El problema de la realidad social. Escritos I. Buenos Aires: Amorrortu.

[Nota]. (2016, febrero 10). Atención: Gana el No en el plebiscito para la paz. Semana. Recuperado de https://www.semana.com/nacion/articulo/plebiscitopara-la-paz-gana-el-no-en-las-votaciones/496486. 